datos de un país industrializado. Aunque la misma curva convexa básica de mortalidad e ingreso se aplique tanto a los países en desarrollo como a los desarrollados, es de esperar que el efecto de las fluctuaciones económicas en la mortalidad se manifieste más fuertemente en los países más pobres. De igual modo es de esperar que el efecto del desempleo, cualquiera que sea el ingreso promedio, se sienta más en países que carecen de seguros por desempleo.

Laporte opina que la principal falla del trabajo de Brenner consiste en no haber tenido en cuenta las características de serie temporal de los datos de nivel macro. Sus resultados indican que los ciclos económicos sí tienen un efecto permanente en la salud de las poblaciones. Paradójicamente, también apuntan a que el crecimiento económico y el aumento del desempleo reducen el riesgo de mortalidad agregado. El que sus resultados no coincidan con los de Brenner no debe traducirse en un rechazo de la hipótesis brenneriana, ya que el argumento original tenía que ver con los efectos de las fluctuaciones económicas en los segmentos más pobres de la sociedad. Bien puede ser que los efectos de los cambios en el ingreso de las personas situadas al pie de la escala distributiva sean muy significativos en función del riesgo de mortalidad. La falta de coincidencia entre Brenner y Laporte quizá se deba a que las medidas de fluctuación económica comúnmente usadas no son sensibles a los efectos de esos ciclos en los grupos de mayor riego. (Laporte A. Do economic cycles have a permanent effect on population health? Revisiting the Brenner hypothesis. Health Econ. 2004;13: 767-79.)

\section{Variabilidad genética del virus de la fiebre amarilla en Brasil}

El virus de la fiebre amarilla (VFA) se transmite por la picadura de mosquitos infectados y produce fiebre hemorrágica grave en las personas. A pesar de existir una vacuna eficaz y segura, la fiebre amarilla aún constituye un problema de salud pública en las áreas tropicales de África y América del Sur. El rápido aumento de casos de esta enfermedad en Brasil y la reinfestación de zonas urbanas con su vector, el mosquito Aedes aegypti, han obligado a desplegar todos los recursos existentes para el control y la vigilancia de esta infección. Durante el año 2000 ocurrieron casos de fiebre amarilla en los alrededores de Brasilia, la capital de Brasil, y en 2001 el VFA se extendió a áreas de Minas Gerais donde hasta el momento no se había registrado su presencia.

En América del Sur, el VFA se mantiene en ciclos enzoóticos en los que intervienen monos y mosquitos de los géneros Haemagogus y Sabethes, propios de los bosques de sombra. En Brasil se han definido tres zonas geográficas en las que circula el VFA: la región endémica, en la que el virus se mantiene en una población móvil de monos y los casos en humanos son pocos y esporádicos; la zona de transición de emergencia, en la que es frecuente el contacto entre las personas y los monos y abundan los mosquitos infectados; y la región epidémica, en la que hay grandes concentraciones de personas y una alta densidad de mosquitos capaces de transmitir la infección, por lo que existe la posibilidad de que aparezcan grandes brotes urbanos de fiebre amarilla.

En este trabajo se estudió la diversidad genética de 79 cepas de VFA aisladas en Brasil entre 1954 y 2001, y se examinó la distribución geográfica de las variantes genéticas con vistas a determinar los patrones de divergencia y la dispersión viral en cinco regiones del país. Las regiones estudiadas fueron: la región amazónica septentrional, la región nororiental (muy seca), la región centrooccidental (pantanos y sabanas), la región sudoriental (la más densamente poblada, con un amplio sistema de carreteras y ferrocarriles) y la región meridional limítrofe con Argentina y Paraguay (la zona más templada).

Se investigaron las características específicas de las 79 cepas estudiadas (ubicación geográfica, fuente de aislamiento, pasos de cultivo y evolución clínica en los casos de infección en humanos). Todas las cepas fueron aisladas inicialmente en ratones lactantes y cultivadas en células C6/36 para crear un banco de cepas en el Instituto Evandro Chagas, en Belém, Brasil. De las cepas virales, 38 (48\%) procedían de personas (24 de ellas, de pacientes fallecidos); 7 (9\%) de monos; y 34 (43\%) de mosquitos, principalmente $H$. janthinomys. Los aislamientos abarcaban un período de 67 años y 12 estados: Amapá (1 aislamiento), Bahia (1 aislamiento), Distrito Federal (1 aislamiento), Goiás (10 aislamientos), Maranhão (6 aislamientos), Minas Gerais (7 aislamientos), Mato Grosso (4 aislamientos), Mato Grosso do Sul (5 aislamientos), Pará (39 aislamientos), Rondônia (2 aislamientos), Roraima (1 aislamiento) y Tocantins (2 aislamientos).

Para el análisis filogenético se extrajo ARN viral y se amplificó mediante los procedimientos de transcripción inversa y reacción en cadena de la polimerasa. El segmento amplificado contenía 595 pares de bases (255 nucleótidos de la región NS5 y 340 de la región no codificante del extremo 3'). Los segmentos nucleotídicos amplificados se secuenciaron y alinearon en busca de mutaciones.

Las cepas de VFA estudiadas pertenecían al genotipo sudamericano I, con la excepción de una cepa aislada en Rondônia que pertenecía al genotipo sudamericano II. 
El árbol filogenético elaborado con las 79 secuencias virales se basa en una región nucleotídica homóloga de la cepa prototipo Asibi (cepa parental de la vacuna 17D), aislada en Ghana en 1927. Las secuencias nucleotídicas de las cepas aisladas en mosquitos y vertebrados se distribuyeron por todo el árbol filogenético. Excepto un aislamiento realizado en 1983 en Rondônia (BeH 413820) y otro realizado en 1975 en Aripuanã, Mato Grosso (BeH 291597), todas las cepas de VFA brasileñas formaron un único clado monofilético. Se encontraron dos subclados fácilmente distinguibles: uno más viejo que abarcaba los aislamientos de Pará realizados entre 1954 y 1968, y otro mayor en el que se ubicaron los restantes aislamientos, realizados entre 1969 y 2001.

La variación genética dentro del subclado dominante de cepas de VFA brasileñas demostró un complejo patrón de relaciones que refleja asociaciones geográficas y temporales. Las relaciones entre las diferentes cepas deben ser objeto de futuros análisis de secuencias más específicos.

La clara distinción genética observada entre los aislamientos anteriores a 1968 (10 en total) y las cepas aisladas posteriormente indica que las cepas más viejas han sido reemplazadas por una nueva línea dominante. Se debe continuar la vigilancia y el análisis de las cepas de VFA de Pará para confirmar si las variantes genéticas representadas en ese subclado se han extinguido o si se mantienen en ciclos aún no descubiertos.

Las pruebas filogenéticas presentadas en este trabajo indican que los casos de fiebre amarilla encontrados en Pará en 1998, en Goiás en 2000 y en Minas Gerais en 2001 son todos parte de una epizootia ininterrumpida que generó variantes genéticas de este virus.

Investigaciones realizadas en 2000 y 2001 indican que el VFA se ha expandido más allá de las áreas tradicionales de esta enzootia y ha alcanzado zonas en las que el virus no se había encontrado en más de un siglo. La aparición de variantes casi idénticas en zonas muy distantes entre sí podría indicar que la diseminación de las variantes genéticas del VFA no se debe al movimiento de los monos o de los mosquitos, sino a las migraciones humanas. Teniendo en cuenta que los mosquitos del género Hamagogus viven en las selvas y son relativamente frágiles, el movimiento de personas y el comercio no deben haber sido la vía de diseminación de mosquitos infectados. Entre 1998 y 2001, el virus puede haber sido llevado de Pará a Goiás y de ahí a Minas Gerais por portadores asintomáticos o por personas infectadas en la fase prodrómica.

La identificación de una cepa procedente de la región occidental de Rondônia (Brazil83) con un alto grado de similitud con las cepas del genotipo sudamericano II (de Perú y Bolivia) indica que los dos genotipos sudamericanos circulan simultáneamente en la parte occidental de Brasil. Las correlaciones ecológicas de este patrón no se conocen aún. Sin embargo, todo parece indicar que en la región fronteriza entre Brasil, Perú y Bolivia pueden encontrarse otros genotipos de VFA.

Un resultado inesperado de este estudio fue la identificación de una cepa vacunal (Brazil75). Este aislamiento se obtuvo de la sangre de un paciente fallecido en Aripuanã, Mato Grosso, que había sido vacunado cinco días antes de enfermarse y murió nueve días después de la vacunación. La secuencia genómica de la cepa Brazil75 se encuentra en estudio para evaluar la posible reversión de la vacuna. A pesar de que no se han realizado estudios controlados para evaluar la seguridad o la eficacia de la vacunación contra la fiebre amarilla en pacientes inmunosuprimidos, este hallazgo resalta la importancia de valorar los antecedentes del paciente antes de la vacunación e indica que pueden haber ocurrido más casos de fiebre amarilla vinculados con la vacuna. (Vasconcelos PFC, et al. Genetic divergence and dispersal of yellow fever virus, Brazil. Emerg Infect Dis [publicación periódica en línea]. 2004;10(9):[21 pantallas]. Hallado en: http://www. cdc.gov/ncidod/EID/vol10no9/04-0197.htm).

\section{El bajo riesgo cardiovascular durante la juventud genera beneficios a largo plazo en mujeres}

Los adultos jóvenes del sexo masculino y los hombres y mujeres de mediana edad con niveles favorables de los principales indicadores de riesgo de enfermedades cardiovasculares (ECV) tendrán a largo plazo mucho menos riesgo de padecer ECV y de morir que sus pares que presentan valores adversos en uno o más de esos factores de riesgo. Sin embargo, en el caso de las mujeres jóvenes, el impacto que puede tener un perfil de riesgo cardiovascular favorable sobre la posterior mortalidad solo se ha estudiado mediante modelos de predicción de riesgo basados únicamente en la enfermedad isquémica del corazón (EIC).

En este trabajo se examinó la asociación de tener un bajo riesgo de EIC/ECV y pocos factores de riesgo individuales en mujeres jóvenes, con la mortalidad a largo plazo por EIC, ECV o por cualquier causa.

En el marco del Proyecto de Detección en la Industria, de la Asociación del Corazón de Chicago, se estudió a 39522 empleados y empleadas de 18 años o más de esa ciudad. Para ello se emplearon métodos estandarizados de examen físico, seguimiento y certificación de muerte. El seguimiento se 